\title{
Clinical utility of clodronate in the prevention and management of osteoporosis in patients intolerant of oral bisphosphonates
}

This article was published in the following Dove Press journal:

Drug Design, Development and Therapy

18 October 2011

Number of times this article has been viewed

\section{Maurizio Muratore \\ Eugenio Quarta \\ Antonella Grimaldi \\ Fabio Calcagnile \\ Laura Quarta}

Department of Rheumatology, Hospital Galateo, San Cesario di Lecce, Italy
Correspondence: M Muratore Department of Rheumatology, Hospital Galateo, 73016 San

Cesario di Lecce, Italy

$\mathrm{Tel}+8322 \mathrm{I} 5442$

Fax +832215442

Email mamuratore@libero.it

\begin{abstract}
Bisphosphonates have a long history in the treatment of osteoporosis and bone-related disease. This review focuses on the use of a specific nonaminobisphosphonate, clodronate, which appears to be much better tolerated than other bisphosphonates and free of high-risk contraindications. Specifically, this paper reviews its use in the prevention of osteoporosis in postmenopausal women, taking into account its tolerability profile and recent safety issues arising regarding the use of bisphosphonates.
\end{abstract}

Keywords: clodronate, bisphosphonates, osteoporosis, bone turnover, menopause, tolerability

\section{Epidemiology and societal cost of osteoporosis}

Osteoporosis is the most common bone disease in humans, characterized by low bone mass, deterioration of bone tissue, disruption of bone architecture, compromised bone strength, and increased bone fracture risk over time. Indeed, in recent years, osteoporosis has become one of the major concerns for health care policies in industrialized countries, where improved life expectancy has greatly increased the average age of the population.

A study from the Italian National Institute of Health has shown that only $50 \%$ of the people who report being affected by osteoporosis are actually affected by the condition, while only $50 \%$ of people truly affected by osteoporosis are shown to have the disorder. ${ }^{1}$ Specifically, data from the Epidemiologic Study on the Prevalence of Osteoporosis (ESOPO) calculated that $23 \%$ of the female population over 40 years and $14 \%$ of the male population over 60 years are affected by osteoporosis. A recent technical report on osteoporosis from the World Health Organization estimates osteoporosis to affect 200 million women worldwide, comprising approximately $10 \%$ of women aged 60 years, $20 \%$ of women aged 70 years, $40 \%$ of women aged 80 years, and two-thirds of women aged 90 years, ${ }^{2}$ accounting for more cases than cancer, heart disease, or stroke combined among the female population. ${ }^{3}$

The most common problems linked to osteoporosis are fractures of the proximal femur, vertebrae, and the distal forearm, with hip fractures being potentially lifethreatening in $10 \%-20 \%$ of cases, and leading to ambulatory disability in $30 \%-40 \%$ of cases within one year of the fracture. ${ }^{1,3}$

Given the relevance of the obvious societal and economical burden of the disease, the European Union has set prevention of osteoporosis among its main health care objectives and prevention policies since the late 1990s. Alongside prevention 
campaigns, international scientific societies have developed a number of guidelines on prevention, treatment, and bone threshold values to address the problem. ${ }^{3}$ The vast bulk of the societal and health care costs incurred by osteoporosis and its complications, ie, fractures, are not imputable to pharmacological costs (about $20 \%$ of total expenditure) but rather to the consequences of undetected osteoporosis (transient and/ or permanent disability, early death that could otherwise be prevented or cured, and rehabilitation costs). ${ }^{1}$

\section{Use of bisphosphonates in osteoporosis}

To date, the most well established class of drugs in the treatment of osteoporosis is the bisphosphonates, which are widely used in the treatment of diseases such as hypercalcemia, cancer-associated bone disease, and Paget's disease, that involve excessive bone resorption and high turnover rates. Bisphosphonates are characterized by a high affinity for bone but not for other tissues, their main cellular targets being mesenchymal cells, osteocytes, osteoblasts, and osteoclast precursors. ${ }^{4,5}$ These agents have the ability to increase bone mineral density, reduce bone turnover markers, and thus decrease the risk of osteoporotic fractures. ${ }^{6}$

\section{Chemistry and pharmacokinetics of bisphosphonates}

Bisphosphonates are synthetic analogs of pyrophosphate, an endogenous regulator of bone mineralization, which contains a nonhydrolyzable P-C-P backbone with two side chains (R1 and R2). The two phosphonate groups are required for binding to bone mineral and for antiresorptive potency. Modification of one or both phosphonate groups significantly reduces the binding affinity as well as antiresorptive potency of the bisphosphonates. The R1 and R2 side chains have a wide range of activities. Acting together with the two phosphonate groups, the presence of a hydroxyl group $(-\mathrm{OH})$ or an amino group $\left(-\mathrm{NH}_{2}\right)$, rather than an $\mathrm{H}$ group in the $\mathrm{R} 1$ chain, enhances binding to calcium minerals. The presence of a nitrogen or amino group in the R2 side chain significantly increases the antiresorptive potency of bisphosphonates and also affects binding to hydroxyapatite. Figure 1 shows the bisphosphonate pathway, and the genes involved in the effects of bisphosphonates on osteoclasts. ${ }^{6}$ Thus, the strength of action of a bisphosphonate, defined as adequate suppression of bone resorption in vivo, results from its ability to inhibit the mevalonate cycle and thus block osteoclastic activity and its affinity for hydroxyapatite.

On this basis, bisphosphonates can be broadly classified into two major classes with distinct mechanisms of action, ie, the non-nitrogen-containing class and the nitrogencontaining class. The earlier non-nitrogen-containing bisphosphonates (eg, clodronate, tiludronate, and etidronate) act by incorporation into adenosine triphosphate, whereas the newer, more potent nitrogen-containing bisphosphonates (eg, pamidronate, alendronate, ibandronate, risedronate, and zoledronate) act by inhibiting farnesyl pyrophosphate synthase in the mevalonate pathway. ${ }^{6}$

\section{Bisphosphonates used in the clinical setting}

In the clinical setting, the most commonly used bisphosphonates are zoledronate, alendronate, pamidronate, risedronate, and clodronate. These agents are available for intravenous, intramuscular (only in Italy), and oral administration. Intravenous and intramuscular administration guarantees $100 \%$ bioavailability (allowing high doses to be reached quickly at the skeletal level), whereas oral administration has the drawback of much lower bioavailability, with considerable intrasubject variability, and in all cases has an absorption of only $0.5 \%-2.0 \%$ of the dose taken. For this reason, oral administration is used only for treatment that requires minimal amounts to control bone turnover, such as in postmenopausal women.,

Bisphosphonates are generally well tolerated, with few side effects, which include gastrointestinal symptoms (nausea, vomiting, diarrhea) and occur more frequently among patients prescribed oral bisphosphonates. However, recent findings that bisphosphonates induce osteonecrosis of the jaw, atrial fibrillation, acute phase response, and renal insufficiency have raised safety and ethical concerns around the use of bisphosphonates. In reality, several clinical investigations addressing the topic have ascribed these effects to aminobisphosphonates, thus excluding the nonaminobisphosphonates.

This review focuses on the use of a specific nonaminobisphosphonate, clodronate, which appears to be much better tolerated than other bisphosphonates and free of high-risk contraindications. Specifically, we will approach the tolerability and safety issues mentioned earlier, compare clodronate with other bisphosphonates, and discuss some of the literature regarding indications for its use in the prevention of osteoporosis, particularly in postmenopausal women.

\section{Therapeutic indications for clodronate}

Clodronate is a well established medication in the treatment of patients with breast cancer to prevent bone metastases and improve survival rates. ${ }^{9}$ Considering that cancers 


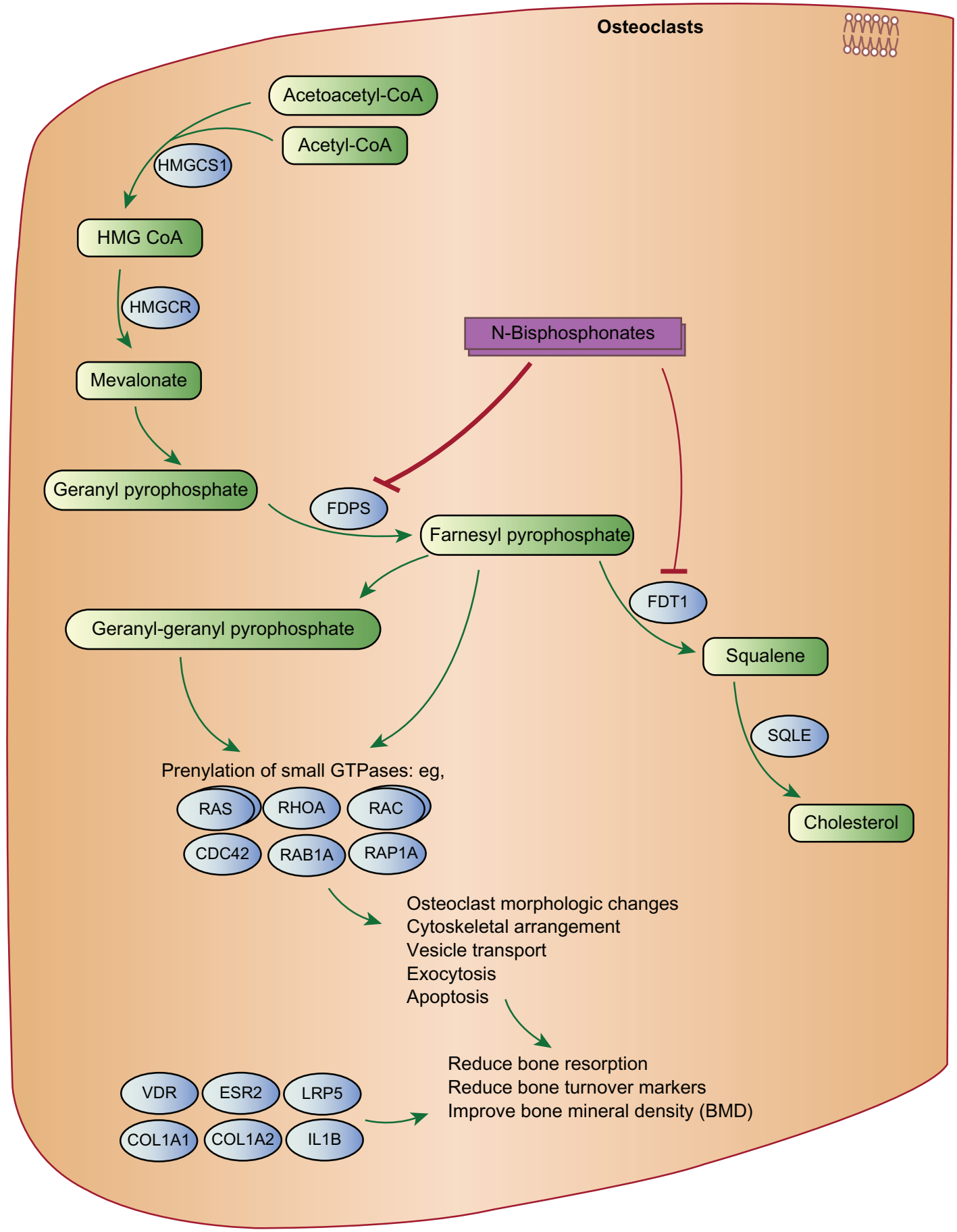

Figure I Bisphosphonate pathway, and the genes involved in the effects of bisphosphonates on osteoclasts.

(C) PharmGKB. Reproduced with permission from PharmGKB and Stanford University. Gong Li, Altman Russ B, Klein TE. Bisphosphonates pathway. Pharmacogenetics and genomics (2009). ${ }^{6}$

metastasized to bone are usually incurable, bisphosphonate therapy is generally used in the palliative setting, and therefore should be well tolerated with minimal side effects. ${ }^{10}$

Although mainly used against cancer-induced bone disease, the undoubted efficacy and relatively low toxicity of clodronate also makes it an attractive candidate for the management of osteoporosis. In addition, while bisphosphonates are usually administered according to a continuous oral schedule for osteoporosis, clodronate is available in several formulations and can be used in a number of different schedules for prevention and treatment of the condition. ${ }^{4}$ Moreover, it appears that the efficacy of clodronate does not depend on the route of administration, but rather on its mode of administration 
(continuous or intermittent). ${ }^{4,11}$ The doses and formulations available are summarized in Table 1.

Oral formulations consist of $400 \mathrm{mg}$ and $800 \mathrm{mg}$ tablets and $400 \mathrm{mg}$ capsules. The intravenous formulation is a $60 \mathrm{mg} / \mathrm{mL}$ concentrate designed for infusion after dilution with normal saline or $5 \%$ glucose solution. For the management of osteoporosis, the usual dosage is 400 or $800 \mathrm{mg} /$ day orally or $100 \mathrm{mg}$ intramuscularly every 7-14 days. The intravenous formulation may be used on a short-term basis at a dosage of $200 \mathrm{mg}$ every 3-4 weeks., ${ }^{4,5}$

Of the clodronate that is resorbed from oral preparations or infused intravenously, about $50 \%$ is excreted unchanged by the kidney. The remainder has a very high affinity for bone tissue, and is rapidly absorbed onto the bone surface. Indeed, its efficacy in the prevention of osteoporosis in postmenopausal women has been documented in several studies that have shown the efficacy of the drug, not only in increasing bone mineral density, but also in reducing fragility-related fractures. ${ }^{12}$

\section{Mechanism of action}

Numerous studies have been conducted in recent years in order to assess the precise mechanisms by which each bisphosphonate inhibits bone resorption, ${ }^{4,13,14}$ and it seems that the specific action of each bisphosphonate depends on its ability to bind rapidly and with high affinity to the bone surface. As for clodronate, in vitro studies have demonstrated its ability to inhibit reversibly the growth and glycolysis of fibroblasts and osteoclasts. Inhibition of osteoclastic activity reduces the firing rate of new bone remodeling units, with an altered balance between bone formation and resorption in favor of the latter, accounting for why use of clodronate is encouraged in the prevention and treatment of postmenopausal osteoporosis. ${ }^{5}$

\section{Historical background}

The first study data date back to $1993^{15,16}$ when a group of patients with osteoporosis treated with oral clodronate at a

Table I Available formulations and doses of clodronate.

\begin{tabular}{lll}
\hline $\begin{array}{l}\text { Administration } \\
\text { route }\end{array}$ & Formulation & Dose \\
\hline Oral & Tablets & $400 \mathrm{mg}$ \\
& & $800 \mathrm{mg}$ \\
& Capsules & $400 \mathrm{mg}$ \\
IV & Injectable solution & $30 \mathrm{mg} / \mathrm{mL}$ \\
IM & Injectable solution & $100 \mathrm{mg} / 3,3 \mathrm{~mL}$ \\
& $(6-12$ vials $)$ & \\
\hline
\end{tabular}

Abbreviations: IV, intravenous; IM, intramuscular. dose of $200-600 \mathrm{mg} /$ day for three months at six-monthly intervals showed an increase in total body calcium after one year of treatment compared with placebo. Clodronate had a positive effect on bone mineral density that persisted for eight months after stopping administration of the drug. The positive action of oral clodronate was confirmed by another study ${ }^{15,17}$ in which postmenopausal women with osteoporosis were treated every two months with $400 \mathrm{mg}$ of clodronate, taken for a total of 12 months. In this study, bone mineral density increased significantly at the lumbar spine compared with untreated patients in whom bone mineral density decreased by about $2 \%$, and these positive effects were already significant after the first six months of therapy. In 1995, a randomized trial by Filipponi et al ${ }^{15,18}$ involving postmenopausal women with osteoporosis showed that six months of cyclical treatment with clodronate for up to four years, intravenously administered at a dose of $200 \mathrm{mg}$ per month, resulted in a significant reduction in markers of bone remodeling, indicating a protective action against loss of bone mass, and these results were significant after 12 months and maintained even at 24 months. Another study conducted in the same year ${ }^{15,19}$ seemed to confirm the effectiveness of intramuscular administration of the drug in preventing bone loss in postmenopausal women with osteoporosis. In particular, Rossini et al showed that after two years of treatment with clodronate, administered at a dose of $100 \mathrm{mg}$ intramuscularly every two weeks (with oral calcium supplementation), the treated group showed significant differences in lumbar and femoral bone mineral density compared with the control group (treated only with calcium supplementation) and a significant reduction in circulating levels of alkaline phosphatase. In 1996, Filipponi et al published an openlabel study ${ }^{18}$ that evaluated changes in bone mineral density in 235 postmenopausal women with osteoporosis treated every three weeks with $200 \mathrm{mg}$ of clodronate intravenously and followed annually for six years, compared with a control group of 183 women observed retrospectively. The results showed a significant increase in bone mineral density in the first year of treatment, an effect maintained over six years and showed the positive effect of the drug in preventing lumbar fractures, particularly in patients with a history of fracture at the beginning of treatment. ${ }^{20}$ Based on these results, a subsequent study evaluated the administration of clodronic acid injected continuously or intermittently, with significant results in the two schedules at both the lumbar spine and the femoral neck. ${ }^{4,11,20}$

However, studies show that the two formulations of clodronate now used in osteoporosis (intramuscular and 
oral) show similar increases in bone mineral density, with slightly higher values for the intramuscular formulation. ${ }^{4}$ In a double-blind, placebo-controlled trial, ${ }^{12,21} 593$ women with postmenopausal or secondary osteoporosis were evaluated for three years. It was demonstrated that the oral administration of clodronate at a dose of $800 \mathrm{mg}$ per day induced a significant increase in bone mineral density at the lumbar spine and total hip, associated with a $46 \%$ reduction in the incidence of vertebral fractures compared with placebo. This reduction reached statistical significance after one year of therapy. In another randomized controlled trial, the $20 \%$ reduction in fracture risk was detected with $800 \mathrm{mg}$ daily of oral clodronate in a group of elderly patients aged $\geq 75$ years. . $^{4,22}$

These studies also assessed the effectiveness of intramuscular clodronate at a dose of $100 \mathrm{mg}$ every week or every two weeks. ${ }^{4,21,22}$ In particular, in a study of 250 women who were 12 months postmenopausal, Domeninguez et al compared weekly intramuscular administration of clodronate $100 \mathrm{mg}$ with administration of the same dose every two weeks, and have found that both regimens achieved a statistically significant improvement in bone mineral density compared with the control group treated only with calcium and vitamin D supplementation. Nevertheless, it seemed that the largest increases in bone mineral density at the lumbar spine and femoral neck was recorded in the patient group treated with clodronate $100 \mathrm{mg}$ per week. ${ }^{23}$ The improvement in bone mineral density and ability of clodronate to reduce the incidence of fractures were confirmed by Frediani et al, who conducted a study in 163 patients with arthritis and corticosteroid-induced osteoporosis. ${ }^{24}$ Therefore, it would appear that bisphosphonates, and clodronate in particular, are characterized by a direct correlation between dose and effect on densitometry. ${ }^{22}$

\section{Anti-inflammatory effects}

In addition to preventing and reducing bone loss, clodronate has extraskeletal biological effects, ie, anti-inflammatory and antiarthritic activity in both animal and human models. In particular, clodronate has demonstrated the anti-inflammatory in vitro effect of nonaminobisphosphonates and the proinflammatory effect of aminobisphosphonates. ${ }^{4,5}$ Itoh et $\mathrm{al}^{25}$ have shown the anti-inflammatory effect of clodronate in vivo, in contrast with alendronate, and this effect seems to be supported by in vivo studies conducted in animals from which have emerged the effects of aminobisphosphonates on interleukin-1, histidine decarboxylase activity, and tumor necrosis factor alpha (TNF- $\alpha),{ }^{26,27}$ as well as the ability of clodronic acid to prevent bone damage to arthritic joints. Beneficial effects have also been observed in rats. ${ }^{28}$

\section{Effects on fracture risk}

The efficacy of oral clodronate in reducing the risk of skeletal fractures was demonstrated in a study by McCloskey et $\mathrm{al}^{12}$ in 593 patients with postmenopausal or secondary osteoporosis and then in a larger sample of approximately 5592 older women with osteoporosis. ${ }^{12,21}$ Other studies have assessed and confirmed the efficacy of clodronate administered intramuscularly to reduce fracture risk, such as the study conducted by Frediani et al in 163 women with rheumatoid arthritis or psoriatic arthritis. ${ }^{12,24}$ Other studies have demonstrated the antifracture efficacy of intramuscular clodronate compared with other bisphosphonates, including alendronic acid. ${ }^{29}$

\section{Pharmacokinetics}

The bioavailability of the oral clodronate formulation is only about $1 \%-2 \%$, which accounts for its low lipophilicity, that prevents transcellular transport, and the highly negative charge, which in turn prevents paracellular transport. When administered intravenously at a dose of $30 \mathrm{mg} /$ day, the concentration in the circulation reaches a peak at the end of a three-hour infusion. ${ }^{15}$ Six percent of the circulating drug is ultrafiltrated, and its elimination is mainly urinary $(60 \%-80 \%$ of the administered dose), with limited elimination through feces $(5 \%)$. Twenty percent of the product remains in the body and most likely where the bone is removed over the years, depending on bone turnover. The rate of deposition on the bone surface is rather fast, similar to calcium and phosphate. Rapid infusion of clodronate may impair kidney function, so it is advisable to administer the drug at a rate lower than $200 \mathrm{mg} /$ hour. ${ }^{15}$ The dose should be adjusted in patients with impaired renal function and creatinine clearance. ${ }^{4}$

\section{Compliance with therapy}

Patient compliance and adherence to therapy is an extremely relevant issue in osteoporosis, as with many other clinical conditions that are perceived by the patient as "silent". Adherence to therapy for osteoporosis is often very poor, with values plunging to $50 \% .{ }^{30-32}$ In particular, the evidence shows that the majority of patients treated with drugs for osteoporosis abandon therapy within the first 6-7 months. ${ }^{33,34}$ Generally, better compliance is obtained by patients with previous fractures or severe osteopenia who apparently would be better motivated by tangible clinical experience and conditions. ${ }^{33-35}$ Another reason for poor patient compliance with osteoporosis 
therapy is the array of gastroesophageal side effects of oral therapy along with the strict recommendations required by oral therapy, such as fasting, keeping of an upright position, large uptake of water with the medication, and lengthy therapy, which can become quite bothersome for the patient, especially for the elderly patient, and polypharmacy, which is generally the case for patients with multiple diseases. ${ }^{36,37}$

However, patient adherence with osteoporosis therapy, and thus improvement of therapeutic results, can be achieved by reducing the frequency of drug administration or increasing the interval between doses..$^{22,38-40}$ On this basis, Frediani et al conducted a study which lasted about two years in patients with postmenopausal osteoporosis treated with clodronate $100 \mathrm{mg}$ intramuscularly once a week or clodronate $100 \mathrm{mg}$ intramuscularly for two consecutive days every two weeks. The results suggest similar effects on bone mineral density with the two administration schedules, but with important implications in clinical practice. In fact, reducing the frequency of administration appeared to improve patient adherence to therapy with a good tolerability profile. Moreover, the inconvenience of pain at the injection site has been overcome through the development of a new formulation of clodronate (higher $\mathrm{pH}$ and addition of lidocaine $)^{41}$ although the intensity of pain symptoms in situ is certainly related to the amount of drug administered (200 mg of clodronate equal to a $6.6 \mathrm{~mL}$ vial). Hence, everything considered, formulation and dosing interval can create the conditions for better patient adherence with treatment protocols and better long-term therapeutic results.

\section{Tolerability and safety profile}

As mentioned, clodronate is generally well tolerated. In 2\%-10\% of cases, gastrointestinal symptoms such as nausea and dyspepsia develop, and have been usually observed in people taking the drug orally and at high doses. ${ }^{4,15}$ Moreover, it is preferable not to administer the drug at a high rate of infusion in order to minimize the risk of renal function and then kidney damage. However, unlike other bisphosphonates, it does not appear to be contraindicated in patients with renal failure, although its dose should be modified according to renal function. ${ }^{4}$ In addition to these aspects, in recent years the use of bisphosphonates has raised concerns about the risk of osteonecrosis of the jaw, atrial fibrillation, and of esophageal cancer, as stated in a recent safety report released by the US Food and Drug Administration. ${ }^{42}$

\section{Osteonecrosis of the jaw}

In 2004, Ruggiero et al performed a retrospective chart review of patients with a diagnosis of refractory osteomyelitis and a history of chronic bisphosphonate therapy. Of a total of 63 patients, 56 had received intravenous bisphosphonates for at least one year, and seven patients were on chronic oral bisphosphonate therapy. The authors concluded that the risk of osteonecrosis of the jaw should alert practitioners to monitor for this previously unrecognized potential complication. An early diagnosis might prevent or reduce the morbidity resulting from advanced destructive lesions of the jaw bone. ${ }^{43}$ The increasing recognition that use of bisphosphonates may be associated with osteonecrosis of the jaw led the American Society for Bone and Mineral Research to appoint a task force to address a number of key questions related to this disorder. The task force defined osteonecrosis of the jaw as the presence of exposed bone in the maxillofacial region that did not heal within eight weeks of identification by a health care provider.

Based on review of both published and unpublished data, the risk of osteonecrosis of the jaw associated with oral bisphosphonate therapy for osteoporosis seems to be low, and estimated to be between one in 10,000 and less than one in 100,000 patient-treatment years. However, the task force recognized that information on the incidence of osteonecrosis of the jaw is rapidly evolving and that the true incidence may be higher. The risk of osteonecrosis of the jaw in patients with cancer treated with high doses of intravenous bisphosphonates is clearly higher, in the range of $1-10$ per 100 patients (depending on duration of therapy). ${ }^{44}$

Complete prevention of this complication is not currently possible. However, dental care before embarking on bisphosphonate therapy reduces this incidence, and nonsurgical dental procedures can prevent new cases. For those who present with painful exposed bone, effective control in a pain-free state without resolution of the exposed bone is $90.1 \%$ effective using a regimen of antibiotics along with $0.12 \%$ chlorhexidine antiseptic mouthwash. ${ }^{45}$ Fortunately, unlike the aminobisphosphonates, clodronate rarely causes osteonecrosis of the jaw and this problem would seem to occur mainly in patients previously treated with aminobisphosphonates. ${ }^{4,46}$

\section{Proinflammatory activity and atrial fibrillation}

Bisphosphonates, as well as preventing and reducing bone loss, have extraskeletal biological effects, ie, anti-inflammatory and antiarthritic activity, in both animal and human models. In particular, it has demonstrated 
the in vitro anti-inflammatory effects of the nonaminobisphosphonates and the proinflammatory effects of the aminobisphosphonates. ${ }^{4,5}$

Several clinical studies have recently shown a potential risk of atrial fibrillation in women with postmenopausal osteoporosis treated with aminobisphosphonates and it seems that this is attributable to a proinflammatory action. ${ }^{47}$ The first alert of the association between bisphosphonates and atrial fibrillation came from the HORIZON study ${ }^{48}$ which evaluated the antifracture efficacy of a single yearly infusion of zoledronate in 3889 women with postmenopausal osteoporosis. Following this study, several meta-analyses of clinical trials have been published, but they covered only a small number of the hundreds of comparative trials evaluating bisphosphonates, few of which mentioned atrial fibrillation. In 2010, a meta-analysis of placebo-controlled trials of bisphosphonates in a total of 26,126 patients with osteoporosis showed an increased risk of atrial fibrillation. ${ }^{49}$ Conversely, a meta-analysis of seven placebo-controlled observational studies of bisphosphonates in patients with osteoporosis in 2010 showed no statistically significant increase in the overall risk of atrial fibrillation. ${ }^{50}$ Our literature search up to mid 2010 found no studies concerning the risk of atrial fibrillation in cancer patients treated with bisphosphonates. Pending publication of more data, the potential risk of atrial fibrillation in some patients treated with bisphosphonates should be taken into account. There is no evidence of an increased risk with a specific bisphosphonate, route of administration, patient subpopulation, or treatment duration. ${ }^{51}$

\section{Other therapeutic effects}

Some experts have even proposed a combination therapy with clodronic acid and alendronic acid to counteract the proinflammatory effects of the latter. ${ }^{52}$ Indeed, it appears that the aminobisphosphonates, by inhibiting the mevalonate pathway, induce rapid and abundant production of proinflammatory cytokines, such as interleukin- 6 and TNF- $\alpha .{ }^{53}$

In murine pain models, clodronate showed central and peripheral antinociceptive effects. ${ }^{54}$ This analgesic effect, associated with the anti-inflammatory action, has led to the use of clodronate in many bone and joint diseases, such as rheumatoid arthritis, ${ }^{55}$ osteoarthritis ${ }^{56,57}$ Paget's disease, ${ }^{58}$ and osteoporosis and osteoporotic fractures. ${ }^{38}$ In particular, clodronate showed a significant improvement in the perception of pain in patients with osteoporotic vertebral fractures, as well as a beneficial effect on bone mass and mechanical strength. ${ }^{4}$

\section{Cost-effectiveness of drugs for osteoporosis}

The main objective today in the treatment of osteoporosis is not only treating osteoporosis and osteoporotic fractures, but also reducing the risk of fractures ${ }^{59}$ with a cost-effective therapy. Numerous studies have demonstrated the efficacy of bisphosphonates in lowering the risk of fracture significantly by reducing bone turnover and maintaining or increasing bone mineral density. ${ }^{12,60-65}$

However, an epidemiological study, known as NORA, conducted in 149,524 postmenopausal women aged 50-104 years (average age approximately 64.5 years) showed that $50 \%$ of fractures were detected in $40 \%$ of the population studied who had a t score consistent with osteopenia ( -1 to -2.5$)$ and that only $20 \%$ of fractures were found in $7 \%$ of the population with osteoporosis ( $\mathrm{t}$ score $<-2.5$ to $<-3.5){ }^{66}$

Most of the fractures would therefore appear to occur in large sections of the population with bone mineral density values above the threshold that defines osteoporosis and in particular in osteopenia ( $\mathrm{t}$ score $<-1.0$ to $<-2.5$ ). ${ }^{67}$ Therefore, the density values alone and in particular the bone mineral density are no longer considered to date the only predictors of fractures. Other important factors appear to be relevant in determining the risk of fracture including clinical risk factors independent of bone mineral density ${ }^{66}$ ie, a history of a previous fracture, family history of hip fracture, glucocorticoid therapy, osteoporosis, and secondary underlying conditions such as rheumatoid arthritis, smoking, and alcohol.

On this basis, the World Health Organization has developed an algorithm known as FRAX ${ }^{\circledR}$ (Fracture Risk Assessment Tool) in order to identify a population with an absolute risk of fracture at 10 years, integrating the weights of independent clinical risk factors and bone mineral density t score values at the femoral neck. ${ }^{68}$

Using algorithms to estimate the absolute 10-year risk, clinicians can define a threshold pharmacological intervention that should be calculated more accurately based on a careful evaluation of the drug economy, ie, the cost-effectiveness of drugs for osteoporosis. ${ }^{69}$

On the other hand, the cost-benefit ratio of therapy could be improved by improving the drug in terms of greater antifracture efficacy and impact in the population and at a lower cost, reducing direct and indirect health care costs and selecting the populations at highest risk of fracture (fracture risk at 10 years of $10 \%, 20 \%$, and $30 \%$ ). 
In particular, an analysis conducted by McCloskey et $\mathrm{al}^{12}$ found that subjects identified as at high risk of fracture with the FRAX algorithm respond to treatment with clodronate taken orally.

\section{Conclusion}

There are many factors to consider when choosing a drug for the treatment of osteoporosis, ie, tolerability, safety, patient compliance with treatment, the drug's ability to improve bone mineral density and significantly reduce the risk of fracture with fewer societal and health costs related to fractures, and also the cost-effectiveness of the drug.

Among the drugs available to date, as stated previously, clodronate seems to have good tolerability and safety. It appears that, unlike other bisphosphonate, this drug reduces the risk of developing osteonecrosis of the jaw. Nevertheless, specialists should fully understand the mechanisms of action of different classes of bisphosphonates, including minimizing unwanted side effects.

In addition, the minor gastrointestinal complications and easy mode of administration, and not least its anti-inflammatory and analgesic effects, would seem to improve compliance and patient adherence to treatment with clodronate. ${ }^{70}$

Given the efficacy of the oral and intramuscular formulations of clodronate in improving bone mineral density and reducing fracture risk, the cost-effectiveness ratio for this drug can be maximized by improving the therapeutic compliance of patients through the employment of several possible regimens weekly, biweekly and last but not least, using the “TWINCARE a month" scheme.

\section{Disclosure}

The authors report no conflicts of interest in this work.

\section{References}

1. ISS: Osteoporosi: una malattia sociale, costi assistenziali, interventi terapeutici.[Osteoporosis: a social disease, healthcare costs, therapeutic interventions]. Available from: http://www.salute.gov.it/resources/ static/primopiano/278/scheda\%20ISS\%20def\%20.pdf. Accessed August 5, 2011. (Italian)

2. Kanis JA. World Health Organization Technical Report. University of Sheffield, UK: 2007.

3. National Osteoporosis Foundation. Clinician's Guide to Prevention and Treatment of Osteoporosis. Washington, DC: National Osteoporosis Foundation; 2010.

4. Frediani B, Cavalieri L, Cremonesi G. Clodronic acid formulations available in Europe and their use in osteoporosis. A review. Clin Drug Invest. 2009;29:359-379.

5. Ghinoi V, Brandi ML. Clodronate: Mechanisms of action on bone remodelling and clinical use in osteometabolic disorders. Expert Opin Pharmacother. 2002;3:1643-1656.

6. Pharmacogenomics Knowledge Base. Available from: http://www. pharmgkb.org/do/serve?objCls=Pathway\&objId=PA154423660\#PGG.
7. Bertoldo F, Dalle Carbonare L, Pancheri S. L'osteonecrosi della mandibola associate alla terapia dei bifosfonati. Bifosfonati. 2007;2: 3-21. Italian.

8. Cremers SC, Pillai G, Papapoulo SE. Pharmacokinetics/pharmacodynamics of bisphosphonates: Use for optimization of intermittent therapy for osteoporosis. Clin Pharmacokinet. 2005;44:551-570.

9. Dando TM, Wiseman LR. Clodronate: A review of its use in the prevention of bone metastases and the management of skeletal complications associated with bone metastases in patients with breast cancer. Drugs Aging. 2004;21:949-962.

10. Diel J, Bergener R, Grotz K. Adverse effects of bisphosphonates: Current issues. J Support Oncol. 2007;5:475-482.

11. Filipponi P, Cristallini S, Rizzello E, et al. Cyclical intravenous clodronate in postmenopausal osteoporosis: Results of a long-term clinical trial. Bone. 1996;18:179-184.

12. McCloskey E, Selby P, Davies M, et al. Clodronate reduces vertebral fracture risk in women with postmenopausal or secondary osteoporosis: Results of a double-blind, placebo controlled 3-year study. J Bone Miner Res. 2004;19:728-736.

13. Benford HL, McGowan NW, Helfrich MH, et al. Visualization of bisphosphonate-induced caspase-3 activity in apoptotic osteoclasts in vitro. Bone. 2001;28:465-473.

14. Solomon CG. Bisphosphonates and osteoporosis. $N$ Engl J Med. 2002;346:642.

15. Brandi ML. Impiego del clodronato nei disordini del metabolismo minerale. Stato dell'arte nell'anno 2000 [Use of clodronate in dysfunction of mineral metabolism. State of the art in the year 2000]. Minerva Med. 2001;92:251-268. (Italian)

16. Chesnut CH. Synthetic Calcitonin, Diphosphonates and Anabolic Steroids in the Treatment of Postmenopausal Osteoporosis. Copenhagen, Denmark: Osteopress; 1984.

17. Giannini S, D’Angelo A, Malvasi L, et al. Effects of one-year cyclical treatment with clodronate on postmenopausal bone loss. Bone. 1993; $14: 137-141$

18. Filipponi P, Pedetti M, Fedeli L, et al. Cyclical clodronate is effective in preventing postmenopausal bone loss: A comparative study with transcutaneous hormone replacement therapy. J Bone Miner Res. 1995;10:697-703.

19. Rossini M, Braga V, Gatti D, Zamberlan N, Bianchini D, Adami S. Intramuscular intermittent clodronate in the treatment of postmenopausal osteoporosis. Bone. 1995:6:606.

20. Filipponi P, Cristallini S, Rizzello E, et al. Cyclical intravenous clodronate in postmenopausal osteoporosis: Results of a long-term clinical trial. Bone. 1996;18:179-184.

21. McCloskey EV, Beneton M, Charlesworth D, et al. Clodronate reduces the incidence of fractures in community-dwelling elderly women unselected for osteoporosis: Results of a double-blind, placebo-controlled randomized study. J Bone Miner Res. 2007;22:135-141.

22. Frediani B. Effects of two administration schemes of intramuscular clodronic acid on bone mineral density. A randomized, open-label, parallel-group study. Clin Drug Investig. 2011;31:43-50.

23. Dominguez LJ, Galioto A, Ferlisi A, et al. Intermittent intramuscular clodronate therapy: A valuable option for older osteoporotic women. Age Ageing. 2005;34:633-636.

24. Frediani B, Falsetti P, Baldi F, et al. Effects of 4-year treatment with onceweekly clodronate on prevention of corticosteroid-induced bone loss and fractures in patients with arthritis: Evaluation with dual-energy x-ray absorptiometry and quantitative ultrasound. Bone. 2003;33: 575-581.

25. Itoh F, Aoyagi S, Kusama H, et al. Effects of clodronate and alendronate on local and systemic changes in bone metabolism in rats with adjuvant arthritis. Inflammation. 2004;28:15-21.

26. Funayama H, Mayanagi $\mathrm{H}$, Takada $\mathrm{H}$, et al. Elevation of histidine decarboxylase activity in the mandible of mice by Prevotella intermedia lipopolysaccharide and its augmentation by an aminobisphosphonate. Arch Oral Biol. 2000;45:787-795.

27. Yamaguchi K, Motegi K, Iwakura Y, et al. Involvement of interleukin-1 in the inflammatory actions of aminobisphosphonates in mice. Br J Pharmacol. 2000;130:1646-1654. 
28. Oelzner P, Kunze A, Henzgen S, et al. High-dose clodronate therapy prevents joint destruction in chronic antigen-induced arthritis of the rat but inhibits bone formation at the axial skeleton. Inflamm Res. 2000;49: 424-433.

29. Muscoso E, Puglisi N, Mamazza C, et al. Antiresorption therapy and reduction in fracture susceptibility in the osteoporotic elderly patient: Open study. Eur Rev Med Pharmacol Sci. 2004;8:97-102.

30. Rossini M, Bianchi G, Di Munno O, et al. Treatment of Osteoporosis in clinical Practice (TOP) Study Group. Determinants of adherence to osteoporosis treatment in clinical practice. Osteoporos Int. 2006;17: 914-921.

31. Berg JS, Dischler J, Wagner DJ, Raia JJ, Palmer-Shevlin N. Medication compliance: A healthcare problem. Ann Pharmacother. 1993;27(Suppl 9): $\mathrm{S} 1-\mathrm{S} 24$.

32. Miller NH. Compliance with treatment regimens in chronic asymptomatic diseases. Am J Med. 1997;102:43-49.

33. Tosteson AN, Grove MR, Hammond CS, et al. Early discontinuation of treatment for osteoporosis. Am J Med. 2003;115:209-216.

34. Turbi C, Herrero-Beaumont G, Acebes JC, et al. Compliance and satisfaction with raloxifene versus alendronate for the treatment of postmenopausal osteoporosis in clinical practice: An open label, prospective, nonrandomized, observational study. Clin Ther. 2004;26:245-256.

35. Lombas C, Hakim C, Zanchetta JR. Compliance with alendronate treatment in an osteoporosis clinic. J Bone Miner Res. 2001;15 Suppl 1:S529.

36. Muratore M, Quarta L, Calcagnile F, Quarta E. "Twice-a-month" clodronate $200 \mathrm{mg}$ IM: A new dosing regimen and improved therapy adherence in the treatment of postmenopausal osteoporosis. Adv Ther. 2010;27:314-320.

37. Penning-van Beest FJ, Erkens JA, Olson M, Herings RM. Determinants of non-compliance with bisphosphonates in women with postmenopausal osteoporosis. Curr Med Res Opin. 2008;24:1337-1344.

38. Herrala J, Puolijoki H, Liippo K, et al. Clodronate is effective in preventing corticosteroid-induced bone loss among asthmatic patients. Bone. 1998;22:577-582.

39. Reginster JY, Adami S, Lakatos P, et al. Efficacy and tolerability of once-monthly oral ibandronate in postmenopausal osteoporosis: 2 year results from the MOBILE study. Ann Rheum Dis. 2006;65:654-661.

40. Miller PD. Optimizing the management of postmenopausal osteoporosis with bisphosphonates: The emerging role of intermittent therapy. Clin Ther. 2005;27:361-376.

41. McCloskey EV, Johansson H, Oden A, et al. Ten-year fracture probability identifies women who will benefit from clodronate therapy - additional results from a double-blind, placebo-controlled randomised study. Osteoporos Int. 2009;20:811-817.

42. www.fda.gov/S a fety/Medwatch/S a fety In formation/ SafetyAlertsforHumanMedicalProducts/ucm264087.htm. Accessed August 5, 2011.

43. Ruggiero SL, Mehrotra B, Rosenberg TJ, Engroff SL. Osteonecrosis of the jaws associated with the use of bisphosphonates: A review of 63 cases. J Oral Maxillofac Surg. 2004;62:527-534.

44. Khosla S, Burr D, Cauley J, et al; American Society for Bone and Mineral Research. Bisphosphonate-associated osteonecrosis of the jaw: Report of a task force of the American Society for Bone and Mineral Research. J Bone Miner Res. 2007;22:1479-1491.

45. Marx RE, Sawatari Y, Fortin M, Broumand V. Bisphosphonate-induced exposed bone (osteonecrosis/osteopetrosis) of the jaws: Risk factors, recognition, prevention, and treatment. J Oral Maxillofac Surg. 2005;63:1567-1575.

46. Diel IJ, Fogelman I, Al-Nawas B, et al. Pathophysiology, risk factors and management of bisphosphonate associated osteonecrosis of the jaw: Is there a diverse relationship of amino- and non-aminobisphosphonates? Crit Rev Oncol Hematol. 2007;64:198-207.

47. Cummings SR, Schwartz AV, Black DM. Alendronate and atrial fibrillation. N Engl J Med. 2007;356:1895-1896.

48. Black DM, Delmas PD, Eastell R, et al; HORIZON Pivotal Fracture Trial. Once-yearly zoledronic acid for treatment of postmenopausal osteoporosis. N Engl J Med. 2007;356:1809-1822.
49. Bhuriya R, Singh M, Molnar J, Arora R, Khosla S. Bisphosphonate use in women and the risk of atrial fibrillation: A systematic review and meta-analysis. Int J Cardiol. 2010;142:213-217.

50. Kim SY, Kim MJ, Cadarette SM, Solomon DH. Bisphosphonates and risk of atrial fibrillation: A meta-analysis. Arthritis Res Ther. 2010;12:R30.

51. [No authors listed]. Bisphosphonates and atrial fibrillation: Clinical trial data suggest possible link. Prescrire Int. 2011;20:96-97.

52. Endo Y, Shibazaki M, Yamaguchi K, et al. Inhibition of inflammatory actions of aminobisphosphonates by dichloromethylene bisphosphonate, a non-aminobisphosphonate. Br J Pharmacol. 1999;126:903-910.

53. Liu L, Igarashi K, Kanzaki H, et al. Clodronate inhibits PGE(2) production in compressed periodontal ligament cells. J Dent Res. 2006;85:757-760

54. Bonabello A, Galmozzi MR, Bruzzese T, et al. Analgesic effect of bisphosphonates in mice. Pain. 2001;91:269-275.

55. Rovetta G, Monteforte P. Efficacy of disodium-clodronate in the management of joint pain in rheumatoid arthritis: Six months open study. Minerva Med. 2003;94:353-357.

56. Saviola G, Santoro L. Clodronate in erosive osteoarthrosis of the hand: Efficacy for pain and function recovery. G Ital Med Lav Ergon. 2000;22:328-331. Italian.

57. Varenna M, Zucchi F, Ghiringhelli D, et al. Intravenous clodronate in the treatment of reflex sympathetic dystrophy syndrome: A randomized, double blind, placebo controlled study. J Rheumatol. 2000;27:1477-1483.

58. Douglas DL, Duckworth T, Russell RG, et al. Effect of dichloromethylene diphosphonate in Paget's disease of bone and in hypercalcaemia due to primary hyperparathyroidism or malignant disease. Lancet. 1980;1:1043-1047.

59. Adami S, Bertoldo F, Brandi ML, et al. Guidelines for the diagnosis, prevention and treatment of osteoporosis. Reumatismo. 2009;61: 260-284. Italian.

60. Minisola S, Nuti R, Rini G, et al. Daily and intermittent oral ibandronate normalize bone turnover and provide significant reduction in vertebral fracture risk: Results from the BONE Study. Osteoporos Int. 2004; 15:792-798

61. Harris ST, Watts NB, Genant HK, et al. Effects of risedronate treatment on vertebral and nonvertebral fractures in women with postmenopausal osteoporosis: A randomized controlled trial. Vertebral Efficacy With Risedronate Therapy (VERT) Study Group. JAMA. 1999;282:1344-1352.

62. Cummings SR, Black DM, Thompson DE, et al. Effect of alendronate on risk of fracture in women with low bone density but without vertebral fractures: Results from the Fracture Intervention Trial. JAMA. 1998;280:2077-2082

63. Reginster J, Minne HW, Sorensen $\mathrm{OH}$, et al. Randomized trial of the effects of risedronate on vertebral fractures in women with established postmenopausal osteoporosis. Vertebral Efficacy with Risedronate Therapy (VERT) Study Group. Osteoporos Int. 2000;11: 83-91

64. McClung MR, Geusens P, Miller PD, et al. Effect of risedronate on the risk of hip fracture in elderly women. Hip Intervention Program Study Group. N Engl J Med. 2001;344:333-340

65. Wainwright SA, Marshall LM, Ensrud KE, et al. Hip fracture in women without osteoporosis. J Clin Endocrinol Metab. 2005;90: 2787-2793.

66. Siris ES, Chen YT, Abbott TA, et al. Bone mineral density thresholds for pharmacological intervention to prevent fractures. Arch Intern Med. 2004; $164: 1108-1112$

67. Kanis JA, Oden A, Johnell O, et al. The use of clinical risk factors enhances the performance of BMD in the prediction of hip and osteoporotic fractures in men and women. Osteoporos Int. 2007; 18:1033-1046.

68. Kanis JA, McCloskey EV, Johansson H, Oden A, Ström O, Borgström F. Development and use of FRAX in osteoporosis. Osteoporos Int. 2010;21 Suppl 2:S407-S413. 
69. Ringe JD, Möller G. Differences in persistence, safety and efficacy of generic and original branded once weekly bisphosphonates in patients with postmenopausal osteoporosis: 1-year results of a retrospective patient chart review analysis. Rheumatol Int. 2009;30:213-221.
70. Kendler DL, Bessette L, Hill CD, et al. Preference and satisfaction with a 6-month subcutaneous injection versus a weekly tablet for treatment of low bone mass. Osteoporos Int. 2010;21:837-846.

\section{Publish your work in this journal}

Drug Design, Development and Therapy is an international, peerreviewed open-access journal that spans the spectrum of drug design and development through to clinical applications. Clinical outcomes, patient safety, and programs for the development and effective, safe, and sustained use of medicines are a feature of the journal, which has also been accepted for indexing on PubMed Central. The manuscript management system is completely online and includes a very quick and fair peer-review system, which is all easy to use. Visit http://www.dovepress.com/testimonials.php to read real quotes from published authors.

Submit your manuscript here: http://www.dovepress.com/drug-design-development-and-therapy-journal 